\title{
Responses to death and dying: primates and other mammals
}

\author{
James R. Anderson ${ }^{1}$ \\ Published online: 4 January 2020 \\ ๑ Japan Monkey Centre and Springer Japan KK, part of Springer Nature 2020
}

\begin{abstract}
Although some definitions of thanatology—broadly definable as the study of death and dying—exclude nonhumans as subjects, recognition of the scientific value of studying how other species respond to sick, injured, dying and dead conspecifics appears to be growing. And whereas earlier literature was largely characterized by anecdotal descriptions and sometimes fanciful interpretations, we now see more rigorous and often quantitative analysis of various behaviors displayed towards conspecifics (and sometimes heterospecifics) at various stages of incapacitation, including death. Studies of social insects in particular have revealed chemical cues that trigger corpse management behaviors, as well as the adaptive value of these behaviors. More recent research on other taxonomic groups (including aquatic and avian species, and mammals) has sought to better document these animals' responses to the dying and dead, to identify influencing factors and underlying mechanisms, and to better understand the physiological, emotional, social and psychological significance of the phenomena observed. This special issue presents original short reports, reviews, and full research articles relating to these topics in New World monkeys, Old World monkeys and apes, as well as equids and proboscids. The range of events, data, hypotheses and proposals presented will hopefully enrich the field and stimulate further developments in comparative evolutionary thanatology.
\end{abstract}

\section{Introduction: definitions, diversity, developments}

Around 10 years ago, while preparing my first ever lecture on the responses of nonhuman animals to dying and dead companions, I started looking for a readily accessible and straightforward definition of thanatology that would help me to introduce the topic. After rejecting several definitions as being too specialized or obtuse, I turned to Wikipedia, where thanatology was described as: "the academic, and often scientific study of death among human beings" (italics added). I decided to use this definition, not only because it was concise and easy to understand, but also because it excludedquite openly—nonhuman species as legitimate subjects for thanatology. The definition continued: “... It investigates the circumstances surrounding a person's death, the grief experienced by the deceased's loved ones, and larger social attitudes towards death such as ritual and memorialization."

James R. Anderson

j.r.anderson@psy.bun.kyoto-u.ac.jp

1 Department of Psychology, Graduate School of Letters, Kyoto University, Yoshida-honmachi, Sakyo-ku, Kyoto 606-8501, Japan
That all seemed clear enough, but as a comparative psychologist interested in cognitive and emotional processes in other species as well as humans, I was struck by the blatant anthropocentrism. In fact, one aim of my lecture was to persuade the audience of the scientific value and significance of a broader "comparative thanatology" (Anderson 2016), the study of dying and death in humans and other animals.

Seven years later, while preparing a new lecture about responses to death in humans and other species, online browsing eventually brought me again to Wikipedia. I was pleasantly surprised to see a markedly different, updated definition of thanatology; it was now simply "the scientific study of death." Gone, the edict that humans are the only proper subjects for thanatology. The new definition continued: “... It investigates the mechanisms and forensic aspects of death, such as bodily changes that accompany death and the postmortem period, as well as wider psychological and social aspects related to death." Also gone, the overemphasis on human bereavement and sociocultural practices surrounding death. Instead, while still acknowledging human issues, the definition of thanatology had been broadened to include (at least implicitly) the study of mechanisms, bodily changes, and psychological and social consequences of death in other species. 
Clearly, the updated definition reflected a growing recognition of the scientific legitimacy and value of research on death-related reactions in other animals. Perhaps the best example of such research is several decades' worth of observational and experimental studies on responses to dead conspecifics in social insects. In species such as ants, termites and honeybees, "corpse management strategies" have evolved that include avoiding, discarding, ingesting and burying dead individuals, and these behaviors have been fruitfully studied from the perspectives of proximate mechanisms (what elicits them; how they develop) and ultimate causes (their phylogeny, and adaptive value). Among the sensory cues that elicit these "necrophoric" behaviors in social insects, chemical signals from corpses have been shown to play a predominant role (Wilson et al. 1958; Sun and Zhou 2013).

Comparable experimental investigations on other taxa are notable by their scarcity, most likely due to greater ethical and cost-related issues. Some examples exist, however, such as Pinel et al.'s (1981) report on group-living laboratory rats' use of bedding material to bury dead conspecifics placed in their test chamber. Few rats bothered to bury bodies that had been dead for only a few hours, whereas most rats buried bodies that were $40-80$ hours old. Further experiments showed that two chemical substances that accumulate in corpses and contribute to the characteristic "smell of death"-putrescine and cadaverine-were strong elicitors of burying behavior.

Chemical cues that elicit specific reactions to corpses are known as necromones. Most readers will be familiar with the unpleasant smell of an animal that has died and started to decompose. The smell is often repugnant enough to initiate action to get relief, either by moving away from the smell, or locating the corpse and disposing of it. Surprisingly, the first experimental study of the ability of putrescine to elicit "escape" behaviors in humans was published relatively recently, and it demonstrated effects even when the putrescine presented was below the threshold of conscious awareness (Wisman and Shrira 2015). To my knowledge, there are no published, controlled studies of the behavioral effects of necromones in nonhuman primates.

Other notable experimental contributions in the currently burgeoning field of comparative thanatology include studies of how corvids (American crows) respond to dead conspecifics compared to heterospecifics (e.g., pigeons), and their rapid learning about where death has occurred and associated stimuli (e.g., a specific person, or a natural predator) (Swift and Marzluff 2015, 2018). Other studies are conducted from a more explicitly applied perspective, for example investigations of the repellant properties of necromones for "problem" species (e.g., sharks: Stroud et al. 2014; cockroaches: Rollo et al. 1994), or potential distress in laboratory rodents/livestock witnessing conspecifics being euthanized/slaughtered (Boivin et al. 2016; Anil et al. 1996, 1997). In parallel, noninvasive, observational studies are accumulating, looking at thanatological responses in various species, including nonhuman primates (see below) and notably cetaceans, resulting in attempts to organize the data and reveal mechanisms and possible adaptive functions (for recent reviews of cetacean research see Bearzi et al. 2018; Reggente et al. 2018).

\section{The past decade}

Back to that first lecture around 10 years ago: I prepared it following the publication of a paper I co-authored with Alasdair Gillies of Blair Drummond Safari Park, in Scotland, and Louise Lock, then my Ph.D. student, in which we described the reactions of the members of small group of chimpanzees to the peaceful death of an old female member of the group (Anderson et al. 2010). At that time the literature on nonhuman primate responses to dead conspecifics was quantitatively and qualitatively quite meagre (see Gonçalves and Carvalho 2019 for a historical overview). It consisted mostly of scattered first- and second-hand descriptions—often quite anthropomorphic—of "grief" reactions to the loss of a companion, and of some monkey and ape mothers continuing to transport and care for their dead infants. A notable exception was Sugiyama et al.'s (2009) analysis of factors contributing to dead infant-carrying in Japanese macaques: a rare example at the time of a hypotheses-driven, quantitative investigation (see Das et al. 2019 for a recent quantitative and qualitative multiple-species review of this behavior).

Concerning great apes, for a long time the best-known thanatology-related reports were probably Jane Goodall's descriptions of chimpanzee mothers carrying and caring for dead infants, and Geza Teleki's account of the responses of group members to an adult male chimpanzee's fatal fall from a tree (van Lawick-Goodall 1968; Teleki 1973). Our report on the death of Pansy, the old female in Blair Drummond (Anderson et al. 2010), was unique in being the first to include video evidence of how chimpanzees responded at the precise moment when a member of their group died. We recorded changes in their behavior not only as the old female's death drew nearer, but also their reactions when she died, and their activity throughout the night when the body was still present. In interpreting our data, we drew parallels with some behaviors seen in humans in the context of peaceful death of a family member or close companion. Our paper, along with an accompanying report of unusually prolonged carrying of dead infants by chimpanzee mothers at Bossou (Biro et al. 2010) attracted remarkable worldwide media attention, and generated new debates about what other species might know and feel about death. Together these 
papers probably helped to spark new life into the field of comparative thanatology, evidenced by a surge of publications on death-related reactions in a wide range of species, not only primates (e.g., Cronin et al. 2011; Fashing et al. 2011; Li et al. 2012; Stewart et al. 2012; Bezerra et al. 2014; Campbell et al. 2016; van Leeuwen et al. 2016; Yang et al. 2016; Porter et al. 2019), but also nonprimate mammals (e.g., giraffe: Bercovitch 2012; Strauss and Muller 2012; dingos: Appleby et al. 2013, hippopotamus: Inman and Leggett 2019). More detailed analyses are now being published, addressing topics such as physiological and psychological mechanisms underlying behavioral responses to the dead and dying, the extent to which other species might experience grief, how they differentiate between what is alive and what is dead, and what aspects of the "death concept"-which takes years to develop in humans-might be shared with nonhumans (Anderson 2011, 2017; King 2013; Gonçalves and Biro 2018; Gonçalves and Carvalho 2019; Bearzi et al. 2018; Reggente et al. 2018; Sun et al. 2018; Swift and Marzluff 2018; Watson and Matsuzawa 2018; Monsó 2019; Stephan 2019); indeed these topics feature repeatedly in this special issue. Below, citations to the online versions of the papers in this issue are in bold.

\section{Papers in the special issue}

Pettitt and Anderson (2019) argue in favor of greater fruitful cross-disciplinary research by primatologists and human evolutionary archeologists. To this aim they present examples of behaviors observed in nonhuman primates confronted with dead or dying individuals, and behavior inferred in ancient humans based on various types of evidence gathered in and around putative prehistoric "burial" sites. Common terms and questions might help to achieve a greater understanding of the evolution of primate thanatological responses, including in modern great apes and humans. This paper builds upon "evolutionary thanatology" as expounded by Anderson et al. (2018). The evolutionary angle is also considered by Bercovitch (2012, 2019), who describes similarities and differences in responses to dead conspecifics in three quite different African mammals (olive baboon, elephant, Thornicroft's giraffe). Drawing on his own and others' observations, Bercovitch proposes that there has been an evolutionary change in the role of oxytocin in groupliving species: it promotes not only mother-infant bonds, but other social bonds too. He proposes testable hypotheses concerning oxytocin levels in mothers and other dead infantcarers, and the likelihood of such behavior in relation to species' social complexity.

Two of several hypotheses that have been proposed to explain transport and care of dead infants ("learning to mother" and "social facilitation"; see Watson and
Matsuzawa 2018) might apply to corpse-directed "play parenting" incidents by a wild, adult female, nulliparous chimpanzee, described by Negrey and Langergraber (2019). One day she was seen transporting, holding, touching and grooming a dead bushbaby, and over a year later she behaved similarly toward a dead 5-month-old infant chimpanzee that she grabbed from the mother. The authors compared her behavior with stick play-thought to resemble doll playseen in immatures and in mature females before they have had their first baby.

Pre- and post-death comparisons of hormonal levels can help clarify the emotional consequences of bereavement (Watson and Matsuzawa 2018). A good example of the value of a combined behavioral and endocrinological approach is Engh et al.'s (2006) report of responses of wild female baboons following the loss of a family member to predation. These females showed increased glucocorticoid levels-indicating stress-whereas females in the same group who had suffered no such loss showed no change in stress levels. Two months after the predation event, during which time bereaved females were observed to extend their social (grooming) network, their hormonal levels were back to normal. In the first similar study on a free-ranging macaque mother carrying a dead infant, Takeshita et al. (2019) observed that she appeared anxious and avoided proximity of other group members. However, the female's fecal glucocorticoid levels rapidly returned to baseline, a result that the authors interpret in terms of dead infant carrying buffering against the stress of losing an infant.

Compared to Old World monkeys and apes, New World monkeys are underrepresented in the primate thanatological literature; reports are largely limited to accounts of infanticide and of relatively short-lived dead-infant carrying (Gonçalves and Carvalho 2019). Trapanese et al. (2019) recorded the postmortem fate of a stillborn infant in a semifree-ranging group of brown capuchin monkeys. The mother was at first highly attentive to it; she transported it, held, groomed and licked it during the first morning. However, as the day progressed, the mother became generally less careful with the corpse, and she eventually started to bite into it and eat it. The next day the mother's older son picked up the abandoned corpse, played with it roughly, and then also started to eat parts of it. Referring to descriptions of infant carcass consumption in other primate species, the authors consider possible nutritional benefits, and they propose that such cannibalism might be a normal, albeit rarely observed, part of the behavioral repertoire.

In the first of three papers focusing on nonprimate species, Mendonça et al. (2019) describe the reactions of a free-ranging adult female horse and other individuals to her fatally injured foal, following a presumed wolf attack. The study population of horses (in Portugal) shows some interesting similarities and differences with aspects of primate 
social organization (Ringhofer et al. 2017). The dominant stallion in the group at first repeatedly tried to herd the injured foal back into the group, but he then switched to trying to prevent the mother from returning to it. After remaining with her dying offspring and contacting and sniffing it frequently, the mother eventually abandoned it and followed her group. One of two young adult females of another group also attended to the foal, contacting and sniffing it, but other horses showed only brief interest and some vigilance. The authors call for further research into horses' cognitive and behavioral responses to death.

Watts (2019) reports 25 cases of responses to corpses and skeletons (of conspecifics and heterospecifics) and dying conspecifics in wild gorillas and chimpanzees. He considers the observed responses from the perspective of "animacy detection malfunction" hypothesis (Gonçalves and Biro 2018), which he concludes can explain most of the cases (though not mothers' immediate abandonment of infants killed by infanticide). He emphasizes the variation in the apes' responses to the dying and dead, which range from interest and "sympathetic concern" to aggressive attacks and partial cannibalism.

Infanticide (also reported by Watts 2019) is a major cause of death in some chimpanzee populations (Anderson 2018). Lowe et al. (2019) report on 33 potentially infanticidal attacks on infants recorded in one community in Uganda over a 24-year period. In most cases the killer was male, and the victim was less than 1 week old. The authors point out that cannibalism of infant corpses was relatively rare (in $26 \%$ of cases with known outcome) and never complete, and conclude that the sexual selection hypothesis explains their data better than competing hypotheses.

Another hypothesis for at least some cases of continued maternal behavior towards dead infants is that it is a "wait and see" strategy of the mother in case the "dead" infant recovers (Watson and Matsuzawa 2018 for primates, Bearzi et al. 2018 for cetaceans). This might happen, for example, if a primate infant is stunned after a fall, or unconscious due to illness. The hypothesis receives clear support from events described by Masi (2019): a wild western gorilla continued to care for her infant after the latter fell out of a tree and appeared (at least to the human observers) to be dead. However, the infant slowly regained both consciousness and mobility, and eventually made a full recovery.

In humans, the death of a family member usually gives rise to expressions of sympathy and social support. To assess whether something similar might be seen in chimpanzees, Goldsborough et al. (2019) analyzed captive chimpanzees' affiliative interactions with an adult female before and after she gave birth to a stillborn baby. She received more affiliation after than before the birth, notably from other chimpanzees who were previously non-affiliative with her, and especially from a female who years previously also had a stillborn infant. The authors cautiously interpret their data in terms of consolation toward the bereaved female.

In a case with some similarities to that of the old female chimpanzee Pansy, described by Anderson et al. (2010), Jakucińska et al. (2019) recorded the reactions of members of a zoo group of chimpanzees to the body of an old female who appeared to have died in her sleep. Females were especially interested in the corpse, with reactions including gentle touching and grooming; males were more likely to simply look at and sniff it, although the youngest male showed some rough handling, including jumping on and hitting it. The authors noted that this was the young male's first experience of death, and he was probably learning about death from the total lack of responsiveness or animacy in the corpse. Over a 9-hour period, the group members visited and manipulated the dead female repeatedly, albeit with decreasing frequency, before her adult daughter finally abandoned her, the last one to do so. One adult male never approached the place of death until after the body was removed.

As already mentioned, most reports of responses to corpses in New World monkeys concern infanticide and dead infant-carrying. A rare instance of responses to a dead adult capuchin monkey in a captive group is presented by De Marco et al. (2019). The freshly dead adult female was found at around 06:30 and briefly removed for inspection; no signs of injury were seen. After the body was returned to the enclosure, the behaviors of the other 12 group members within $1 \mathrm{~m}$ of it were recorded. Photographs in the article show examples of touching, lifting and pulling on a limb or the tail, lifting the head, dragging and grooming the corpse; such behaviors were most frequent in the first hour. The dead female's adult daughter and other kin were especially in attendance, but physical contacts with the body diminished over the 5-hour period, after which it was permanently removed. The authors discuss the influence of kinship, age and prior experience on reactions to corpses, and they note the absence of any signs of alarm or distress.

The special issue closes with two articles on wild elephants, African and Asian. Accounts of elephants' responses to dying and dead conspecifics have raised many questions about the level of understanding of death, memory and the significance of some reported behaviors (including partial covering of fresh corpses, and intense investigation of old bones and tusks) in these large-brained, highly socially complex mammals (see, e.g., Douglas-Hamilton et al. 2006; McComb et al. 2006; Hart et al. 2008; Poole and Moss 2008). Goldenberg and Wittemyer (2019) review 32 cases in the literature of African elephants responding to conspecific carcasses at various stages of decay. The most frequent behaviors were touching, approaching and investigating; mounting attempts and vocalizations were infrequent and elicited only by very fresh carcasses. Goldenberg and Wittemyer also refer to attempts to lift the carcass, and to 
"cover" it, presumably with vegetation. The authors contribute new data of their own: close associates as well as less closely bonded individuals showed intense interest in the carcass of an old matriarch (estimated age: 55 years), and fresh wounds suggested attempts, possibly by a large bull, to lift her. Finally, the results of two trials presenting wild elephants with bones of elephants, giraffe and cape buffalo are briefly reported: the elephants showed interest only in bones of their own species, recalling McComb et al.'s (2006) findings when elephants were presented with skulls of elephants, rhinoceros and buffalo.

In the first scientific report on responses to dead and dying conspecifics by Asian elephants, Sharma et al. (2019) describe reactions to a dying newborn calf, an injured and dying calf, and a dead adult female, in southern India. The authors describe repeated "kick-and-support" behaviour by the mother of the dying newborn, with attempts to help and other interactions by two older daughters. In the week following the newborn's death, the mother was often seen around the same place. Similar attempts to get an injured and dying calf to stand up were made by another adult female (relationship to the calf unknown), who gave a loud "trumpet" call when the calf-which might have been attacked by a tiger-collapsed onto its knees. She quietly watched from a distance as a veterinary team conducted an on-site autopsy on the dead calf, and she remained around $100 \mathrm{~m}$ away from the fire on which the calf's body was cremated. In the third case, two adult females were found beside a recently dead old adult female. One female walked repeatedly around the carcass in a circular path, without touching it, while the other foraged nearby. After autopsy, the body was left in situ, but no further sightings of elephants were recorded. The authors discuss individual differences in responses to dying and dead conspecifics, and compare and contrast African and Asian elephants.

\section{Conclusion}

In conclusion, one aim of this collection of original papers is to encourage researchers to give further consideration to the effects of death on the living, regardless of their study species. By recording, analyzing, reporting and discussing death-related behaviors observed in different populations and species, and in various contexts, we can work towards greater understanding of the ontogeny and phylogeny of reactions to death. Physiological, emotional, social and cognitive factors are all relevant to understanding how other organisms not only perceive death, but how they cope with the various challenges posed by death. This endeavor does not have to be merely an academic pursuit; it can be of practical value, for example in terms of education, and management of captive nonhuman populations.
Postscript On the day of submitting this editorial (18 December 2019), Wikipedia states that: "Thanatology ... is the scientific study of death and the losses brought about as a result. It investigates the mechanisms and forensic aspects of death, such as bodily changes that accompany death and the post-mortem period, as well as wider psychological and social aspects related to death" (https:// en.wikipedia.org/wiki/Thanatology). The statement goes on to acknowledge the interdisciplinary nature of the field, another aspect that is evident in many of the contributions and citations in this special issue.

Acknowledgements I thank everyone at Primates who helped in bringing the special issue to completion, all the contributors for their papers, and the many people who kindly acted as reviewers. I also thank several contributors for stimulating face-to-face discussions on thanatological issues. Several of these discussions took place during conferences in Europe and Japan, including the Kyoto Workshops on Evolutionary Psychology, for which Prof. Tetsuro Matsuzawa has arranged gratefully received financial and logistical support. During preparation of the special issue and the editorial, I received support from JSPS KAKENHI Grant No. 18K18693.

\section{References}

Anderson JR (2011) A primatological perspective on death. Am J Primatol 73:410-414

Anderson JR (2016) Comparative thanatology. Curr Biol 26:R553-R556

Anderson JR (2017) Comparative evolutionary thanatology of grief, with special reference to nonhuman primates. Jpn Rev Cult Anthropol 18:173-189

Anderson JR (2018) Chimpanzees and death. Phil Trans R Soc B 373:20170257. https://doi.org/10.1098/rstb.2017.0257

Anderson JR, Gillies JR, Lock LC (2010) Pan thanatology. Curr Biol 20:R349-R351

Anderson JR, Biro D, Pettitt P (2018) Evolutionary thanatology. Phil Trans R Soc B 373:20170262. https://doi.org/10.1098/ rstb.2017.0262

Anil MH, Preston J, McKinstry JL, Rodway RG, Brown SN (1996) An assessment of stress in sheep caused by watching slaughter of other sheep. Anim Welf 5:435-441

Anil MH, McKinstry JL, Field M, Rodway RG (1997) Lack of evidence for stress being caused to pigs by witnessing the slaughter of conspecifics. Anim Welf 6:3-8

Appleby R, Smith B, Jones D (2013) Observations of a free-ranging adult female dingo (Canis dingo) and littermates' responses to the death of a pup. Behav Process 96:42-46

Bearzi G, Kerem D, Furey NB, Pitman NB, Rendell L, Reeves RR (2018) Whale and dolphin behavioural responses to dead conspecifics. Zoology 128:1-15

Bercovitch FB (2012) Giraffe cow reaction to the death of her newborn calf. Afr J Ecol 51:376-379

Bercovitch FB (2019) A comparative perspective on the evolution of mammalian reactions to dead conspecifics. Primates. https:// doi.org/10.1007/s10329-019-00722-3

Bezerra BM, Keasey MP, Schiel N, da Silva Souto A (2014) Responses towards a dying adult group member in a wild New World monkey. Primates 55:185-188 
Biro D, Humle T, Koops K, Sousa C, Hayashi M, Matsuzawa T (2010) Chimpanzee mothers at Bossou, Guinea carry the mummified remains of their dead infants. Curr Biol 20:R351-R352

Boivin GP, Bottomley MA, Grobe N (2016) Responses of male C57BL/6 N mice to observing the euthanasia of other mice. J Am Assoc Lab Anim Sci 55:406-411

Campbell LAD, Tkaczynski PJ, Mouna M, Qarro M, Waterman J, Majolo B (2016) Behavioral responses to injury and death in wild Barbary macaques. Primates 57:309-315

Cronin KA, van Leeuwen EJC, Mulenga IC, Bodamer MD (2011) Behavioral response of a chimpanzee mother toward her dead infant. Am J Primatol 73:415-421

Das S, Erinjery JJ, Desai N, Mohan K, Kumara HN, Singh M (2019) Deceased-infant carrying in nonhuman anthropoids: insights from systematic analysis and case studies of bonnet macaques (Macaca radiata) and lion-tailed macaques (Macaca silenus). J Comp Psychol 133:156-170

De Marco A, Cozzolino R, Thierry B (2019) Responses to a dead companion in a captive group of tufted capuchins (Sapajus apella). Primates. https://doi.org/10.1007/s10329-019-00743-y

Douglas-Hamilton I, Bhalla S, Wittemyer G, Vollrath F (2006) Behavioural reactions of elephants towards a dying and deceased matriarch. Appl Anim Behav Res 100:87-102

Fashing PJ, Nguyen N, Barry TS, Goodale CB, Burke RJ, Jones SCZ, Kerby JT, Lee LM, Nurmi NO, Venkataraman VV (2011) Death among geladas (Theropithecus gelada): a broader perspective on mummified infants and primate thanatology. Am J Primatol 73:405-409

Goldenberg SZ, Wittemyer G (2019) Elephant behavior toward the dead: a review and insights from field observations. Primates. https://doi.org/10.1007/s10329-019-00766-5

Goldsborough Z, van Leeuwen EJC, Kolff KWT, de Waal FBM, Webb CE (2019) Do chimpanzees (Pan troglodytes) console a bereaved mother? Primates. https://doi.org/10.1007/s1032 9-019-00752-x

Gonçalves A, Biro D (2018) Comparative thanatology, an integrative approach: exploring sensory/cognitive aspects of death recognition in vertebrates and invertebrates. Phil Trans R Soc B 373:20170263. https://doi.org/10.1098/rstb.2017.0263

Gonçalves A, Carvalho S (2019) Death among primates: a critical review of non-human primate interactions towards their dead and dying. Biol Rev 94:1502-1529

Hart BL, Hart LA, Pinter-Wollman N (2008) Large brains and cognition: Where do elephants fit in? Neurosci Biobehav Rev 32:86-98

Inman VL, Leggett KEA (2019) Observations on the response of a pod of hippos to a dead juvenile hippo (Hippopotamus amphibius, Linnaeus 1758). Afr J Ecol. https://doi.org/10.1111/aje.12644

Jakucińska A, Trojan M, Sikorska J, Farley D (2019) Reaction to the death of the oldest female in a group of chimpanzees at the Municipal Zoological Garden, Warsaw. Primates. https://doi. org/10.1007/s10329-019-00772-7

King BJ (2013) How animals grieve. The University of Chicago Press, Chicago

Li T, Ren B, Li D, Zhang Y, Li M (2012) Maternal responses to dead infants in Yunnan snub-nosed monkey (Rhinopithecus bieti) in the Baimaxueshan Nature Reserve, Yunnan, China. Primates 53:127-132

Lowe AE, Hobaiter C, Asiimwe C, Zuberbühler K, Newton-Fisher NE (2019) Intra-community infanticide in wild, eastern chimpanzees: a 24-year review. Primates. https://doi.org/10.1007/s10329-01900730-3

Masi S (2019) Reaction to allospecific death and to an unanimated gorilla infant in wild western gorillas: insights into death recognition and prolonged maternal carrying. Primates. https://doi. org/10.1007/s10329-019-00745-w
McComb K, Baker L, Moss C (2006) African elephants show high levels of interest in the skulls and ivory of their own species. Biol Lett 2:26-28

Mendonça RS, Ringhofer M, Pinto P, Inoue S, Hirata S (2019) Feral horses' (Equus ferus caballus) behavior toward dying and dead conspecifics. Primates. https://doi.org/10.1007/s10329-01900728-x

Monsó S (2019) How to tell if animals can understand death. Erkenntnis. https://doi.org/10.1007/s10670-019-00187-2

Negrey JD, Langergraber KE (2019) Corpse-directed play parenting by a sterile adult female chimpanzee. Primates. https://doi. org/10.1007/s10329-019-00734-z

Pettitt P, Anderson JR (2019) Primate thanatology and hominoid mortuary activity. Primates. https://doi.org/10.1007/sd103 29-019-00769-2

Pinel JPJ, Gorzalka BB, Ladak F (1981) Cadaverine and putrescine initiate the burial of dead conspecifics by rats. Physiol Behav 27:819-824

Pool JH, Moss CJ (2008) Elephant sociality and complexity: the scientific evidence. In: Wemmer C, Christen CA (eds) Elephants and ethics: toward a morality of coexistence. Johns Hopkins University Press, Baltimore, pp 69-98

Porter A, Eckardt W, VecellioV, Guschanski K, Niehoff PP, NgoboAs-Ibungu U, Pekeyake RN, Stoinski T, Caillaud D (2019) Behavioral responses around conspecific corpses in adult eastern gorillas (Gorilla beringei spp.). PeerJ. https://doi. org/10.7717/peerj.6655

Reggente MALV, Papale E, McGinty N, Eddy L, de Lucia GA, Bertulli CG (2018) Social relationships and death-related behaviour in aquatic mammals: a systematic review. Phil Trans R Soc B 373:20170260. https://doi.org/10.1098/rstb.2017.0260

Ringhofer M, Inoue S, Mendonça RS, Pereira C, Matsuzawa T, Hirata $S$, Yamamoto S (2017) Comparison of the social systems of primates and feral horses: data from a newly established horse research site on Serra D'Arga, northern Portugal. Primates 58:479-484

Rollo CD, Czyzewska E, Borden JH (1994) Fatty acid necromones for cockroaches. Naturwissenschaften 81:409-410

Sharma N, Sharma Pokharel S, Kohshima S, Sukumar R (2019) Behavioural responses of free-ranging Asian elephants (Elephas maximus) towards dying and dead conspecifics. Primates. https://doi. org/10.1007/s10329-019-00739-8

Stephan C (2019) Attached beyond death: wild female western lowland gorilla (Gorilla gorilla gorilla) carries and cares for mummified infant. Afr J Ecol. https://doi.org/10.1111/aje.12706

Stewart FA, Piel AK, O'Malley RC (2012) Responses of chimpanzees to a recently dead community member at Gombe National Park, Tanzania. Am J Primatol 74:1-7

Strauss MKL, Muller Z (2012) Giraffe mothers in East Africa linger for days near the remains of their dead calves. Afr J Ecol 51:506-509

Stroud EM, O'Connell CP, Rice PH, Snow NH, Barnes BB, Elshaer MR, Hanson JE (2014) Chemical shark repellent: Myth or fact? The effect of a shark necromone on shark feeding behavior. Ocean Coast Manag 97:50-57

Sun Q, Zhou X (2013) Corpse management in social insects. Int J Biol Sci 9:313-321. https://doi.org/10.7150/ijbs.5871

Sun Q, Haynes KF, Zhou X (2018) Managing the risks and rewards of death in eusocial insects. Phil Trans R Soc B 373:20170258. https ://doi.org/10.1098/rstb.2017.0258

Swift KN, Marzluff JM (2015) Wild American crows gather around their dead to learn about danger. Anim Behav 109:187-197. https ://doi.org/10.1016/j.anbehav.2015.08.021

Swift KN, Marzluff JM (2018) Occurrence and variability of tactile interactions between wild American crows and dead conspecifics. Phil Trans R Soc B 373:20170259. https://doi.org/10.1098/ rstb.2017.0259 
Takeshita RSC, Huffman MA, Kinoshita K, Bercovitch FB (2019) Changes in social behavior and fecal glucocorticoids in a Japanese macaque (Macaca fuscata) carrying her dead infant. Primates. https://doi.org/10.1007/s10329-019-00753w

Teleki G (1973) Group response to the accidental death of a chimpanzee in Gombe National Park. Folia Primatol 20-81-94

Trapanese C, Bey M, Tonachella G, Meunier H, Masi S (2019) Prolonged care and cannibalism of infant corpse by relatives in semifree-ranging capuchin monkeys. Primates. https://doi.org/10.1007/ s10329-019-00747-8

van Lawick-Goodall J (1968) The behaviour of free-living chimpanzees in the Gombe Stream Reserve. Anim Behav Monogr 1:161-311

Van Leeuwen EJC, Mulenga IC, Bodamer MD, Cronin KA (2016) Chimpanzees' responses to the dead body of a 9-year-old group member. Am J Primatol 78:914-922

Watson CFI, Matsuzawa T (2018) Behaviour of nonhuman primate mothers toward their dead infants: uncovering mechanisms. Phil Trans R Soc B 373:20170261. https://doi.org/10.1098/ rstb.2017.0261
Watts DP (2019) Responses to dead and dying conspecifics and heterospecifics by wild mountain gorillas (Gorilla beringei beringei) and chimpanzees (Pan troglodytes schweinfurthii). Primates. https ://doi.org/10.1007/s10329-019-00735-y

Wilson EO, Durlach NI, Roth LM (1958) Chemical releaser of necrophoric behavior in ants. Psyche 65:108-114

Wisman A, Shrira I (2015) The smell of death: evidence that putrescine elicits threat management mechanisms. Front Psychol 6:1274. https://doi.org/10.3389/fpsyg.2015.01274

Yang B, Anderson JR, Li BG (2016) Tending a dying adult in a wild multi-level primate society. Curr Biol 26:R403-R404

Publisher's Note Springer Nature remains neutral with regard to jurisdictional claims in published maps and institutional affiliations. 